\title{
Development of Stability Indicating TLC- Densitometry Method of Edaravone Using QbD Approach: Degradation Kinetic Study
}

\author{
Madhuri Baghel ${ }^{1}$, Sadhana Rajput ${ }^{2 *}$ \\ ${ }^{1}$ Centre of Relevance ad Excellence in Novel Drug Delivery Systems, Faculty of Pharmacy, The Maharaja Sayajirao University of \\ Baroda, Vadodara- 390002, Gujarat, INDIA. \\ ${ }^{2}$ Centre of Relevance and Excellence in Novel Drug Delivery System, Faculty of Pharmacy, G. H. Patel Building, Donor's Plaza, The \\ Maharaja Sayajirao University of Baroda, Fatehgunj, Vadodara - 390002, Gujarat, INDIA.
}

\begin{abstract}
Objective: The objective of present method was to utilize risk based and systematic Quality by design approach for development of selective, sensitive, precise, accurate and robust stability-indicating TLC-densitometry for quantification of Edaravone and its degradation products. Method: The TLC-densitometric analysis was carried out in the absorbance mode at $244 \mathrm{~nm}$ using solvent system petroleum ether: ethyl acetate: glacial acetic acid $(6 \mathrm{ml}: 4 \mathrm{ml}: 10 \mu \mathrm{l} / \mathrm{v} / \mathrm{v})$. This system was found to give compact and well resolved spot for Edaravone at an $\mathrm{Rf}$ value of $0.46 \pm 0.21$. Results: Edaravone undergoes significant degradation when subjected to stress degradation in acid, base, neutral, oxidative, photolytic, dry heat induced and accelerated humidity/temperature degradation conditions. The method was validated according to $\mathrm{ICH}$ guideline. Linearity was found in the range of $04-24 \mu \mathrm{g} / \mathrm{band}$. The LOD and LOQ for Edaravone were $0.327 \mu \mathrm{g} / \mathrm{band}$ and $0.989 \mu \mathrm{g} / \mathrm{b}$ and respectively. No interference was observed from excipients in formulation as well as degradation product, indicating specificity of the method. Moreover, the proposed method was also utilized to investigate the kinetics of acid, base, neutral and oxidative degradation process at different concentrations and temperatures. The kinetics of degradation profile was determined using linear and nonlinear regression analysis. The rate constants and half-life were calculated.
\end{abstract}

Key words: Edaravone, CNX approach, ObD, SIAMs, TLC-densitometry.

\section{INTRODUCTION}

Edaravone (EDA, Radicut ${ }^{\circledR}$, MCI-186, developed by Mitsubishi Tanabe Pharma Corporation, Osaka, Japan) has wide therapeutic time window. ${ }^{1}$ EDA (3-methyl-1-phenyl-2-pyrazolin-5-one) is neuroprotective agent that has been widely used for the treatment of acute embolic stroke in Japan since 2001. ${ }^{2}$ This compound possesses potent free radical scavenging and antioxidant actions by inhibiting hydroxyl radical dependent and independent lipid peroxidation. ${ }^{3,4}$ Unlike other free radical scavengers, EDA (Figure 1) readily crosses the blood-brain barrier. $^{5}$ Previously, it was reported that zEDA may be potentially useful in prevention of many diseases occurred by ROS. ${ }^{6,7}$
Some methods have been reported for estimation of EDA. These include UV spectrophotometric, ${ }^{8}$ fluorescent assay, ${ }^{9}$ HPLC, ${ }^{10-12}$ HPTLC $^{13}$ and LC-MS/MS. ${ }^{14}$ The HPTLC method was developed for in vitro Estimation of EDA in human plasma ${ }^{13}$ and to the best of our knowledge no Stability indicating assay method have ever been reported. Hence the aim of present study was to develop stability indicating TLC-densitometry method for quantification of EDA and its degradation products (DPs) by implementing systematic QbD approach and to investigate the kinetics of degradation.
Submission Date: 01-12-2016; Revision Date: 03-01-2017; Accepted Date: 15-02-2017

DOI: 10.5530/ijper.51.2s.51 Correspondence: Sadhana Rajput, Quality Assurance Laboratory, Centre of Relevance and Excellence in Novel Drug Delivery System, Faculty of Pharmacy, G. H. Patel Building, Donor's Plaza, The Maharaja Sayajirao University of Baroda, Fatehgunj, Vadodara-390002, Gujarat, INDIA.

Phone: 02652750605

E-mail: sjrajput@gmail.com

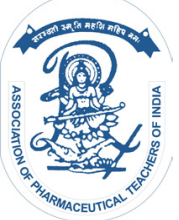

www.ijper.org 


\section{EXPERIMENTAL}

\section{Chemicals and reagents}

The EDA bulk drug and its formulation (ARAVON IV infusion by Sun Pharmaceuticals Ind. Ltd. containing $1.5 \mathrm{mg} / \mathrm{ml}$ of EDA) were purchased from Sigma Aldrich Co, St Louis, USA and local pharmacy respectively. AR grade petroleum ether, ethyl acetate, glacial acetic acid and methanol were procured from Spectrochem Pvt. Ltd., Mumbai. Precoated silica gel aluminum plate $60 \mathrm{~F}_{254},(20 \times 20 \mathrm{~cm})$ were procured from Merck, Darmstadt, Germany.

\section{Instrumentation and chromatographic conditions}

TLC-densitometry was carried out with a CAMAG TLC Scanner 3 fitted with win CATS 1.4.0 chromatography manager software and data analysis was performed with Design Expert 7.0 software. Chromatographic separation was achieved on pre-coated silica gel aluminum plate $60 \mathrm{~F}_{254}$, $(20 \mathrm{X} 20 \mathrm{~cm}$; Merck, Darmstadt, Germany), that were prewashed by methanol and activated at $80^{\circ} \mathrm{C}$ for $20 \mathrm{~m}$ prior to chromatographic separation. The samples were pre-filtered through a $0.2 \mu$ nylon membrane syringe filter before application. The application rate was maintained constantly at $150 \mathrm{~nL} \mathrm{~s}-1$ and the bands spaces were maintained automatically by the software. Samples were applied to the pre-coated TLC plates using spray on technique of CAMAG LINOMAT $\mathrm{V}$ under the flow of nitrogen gas and developed in a CAMAG $20 \mathrm{~cm}$ X $20 \mathrm{~cm}$ twin trough glass chambers pre-saturated with the mobile phase to a distance of 89 $\mathrm{mm}$. The mobile phase consisted of petroleum etherethyl acetate-glacial acetic acid (GAA) $(6 \mathrm{ml}: 4 \mathrm{ml}: 10 \mu \mathrm{l}$ $\mathrm{v} / \mathrm{v} / \mathrm{v})$. After development the TLC plates were dried and scanned on Camag TLC scanner 3 in the absorbance mode at $244 \mathrm{~nm}$.

\section{Preparation of standard, stock and sample solutions}

Stock solutions were prepared in acetonitrile $(1 \mathrm{mg} / \mathrm{ml})$ for quantitation of the EDA in bulk and in commercial dosage forms (Aravon injection, Sun Pharmaceuticals Ind. Ltd.). To analyze the stressed samples suitable dilutions were made in mobile phase to obtain the final concentration of $12 \mu \mathrm{g} / \mathrm{b}$ and with respect to EDA. Same aliquots of EDA were prepared for recovery studies and assay of marketed formulation.

\section{Preparation of degradation products (DPs)}

For the stress degradation studies, different stress conditions were used for EDA bulk drug. Placebo samples (without drug) were also prepared for comparison with the stress degradation samples. $1 \mathrm{mg} / \mathrm{ml}$ of EDA in freshly prepared $0.05 \mathrm{~N} \mathrm{HCl} / 0.8 \mathrm{~N} \mathrm{NaOH}$ was prepared and was refluxed at $80^{\circ} \mathrm{C}$ in dark for $180 \mathrm{~m}$ for acid and base degradation. For neutral degradation sample was prepared in double distilled water and refluxed at $80^{\circ} \mathrm{C}$ in dark for $7 \mathrm{hrs}$. Aliquot of $2 \mathrm{~mL}$ of these samples were withdrawn neutralized with $\mathrm{NaOH} / \mathrm{HCl}$ and stored in freezer before analysis. $1 \mathrm{mg} / \mathrm{ml}$ of EDA was prepared in $6 \% \mathrm{H}_{2} \mathrm{O}_{2}$ by the aid of ultra-sonication and was kept at room temperature in dark for $45 \mathrm{~m}$ for oxidative degradation. For photolytic degradation solution of $1 \mathrm{mg} / \mathrm{ml}$ of EDA in acetonitrile was exposed to $5382 \mathrm{LUX}$ and $144 \mathrm{UW} / \mathrm{cm}^{2}$ for 21 days. Solid drug was spread in $1 \mathrm{~mm}$ thickness on a petridish and placed in oven at $80^{\circ} \mathrm{C}$ for 21 days under dry heat condition in the dark for dry heat induced degradation. For thermalHumidity induced degradation solid drug was placed in Stability Chamber at $40^{\circ} \mathrm{C} \pm 2^{\circ} \mathrm{C}$ and $75 \pm 5 \% \mathrm{RH}$ for 21 days.

All the degradation samples were suitably diluted with mobile phase to make final concentration of $12 \mu \mathrm{g} /$ band, filtered using $0.2 \mu$ nylon membrane syringe filter before application.

\section{Method development and optimization by risk based and QbD approach}

\section{Analytical Target Profile (ATP)}

The Analytical Target Profile (ATP) of the present work was to develop stability indicating TLC-densitometry method that shows well resolved chromatogram of EDA and DPs.

\section{Preliminary investigations}

To get separation among EDA and DPs various non polar solvents were tried along with ethyl acetate because when ethyl acetate was used alone, all components were travelled with mobile phase. Chloroform, hexane, petroleum ether and toluene were tried among nonpolar organic phase. Petroleum ether gives satisfactory result. To remove tailing and quenching of spot glacial acetic acid was added as third component.

Risk assessment by cause- effect relationship and CNX approach

The knowledge accumulated during the preliminary investigation provides inputs for risk assessment by using tools like Ishikawa/Fishbone diagram and CauseEffect Risk Assessment Matrix with $\mathrm{CNX}^{15}$ approach.

\section{Design of Experiments}

Box-Behnken design (BBD) design matrix with 17 runs including five center points was used to evaluate the main and interaction effects of the significant factors selected after CNX risk assessment. 


\section{Method validation}

The present method was validated according to the $\mathrm{ICH}$ Q2(R1) guideline. ${ }^{16}$

\section{Application of developed HPTLC method}

The marketed formulation was analyzed for drug content to determine the possibility of excipient interference. Stress degradation was carried out in the same way as described for bulk drug and \% degradation was calculated.

\section{Degradation kinetics study}

EDA solutions were prepared at a concentration of $1 \mathrm{mg} / \mathrm{mL}$ with variable strength of acid $(\mathrm{HCl})$, Base $(\mathrm{NaOH})$ and $\mathrm{H}_{2} \mathrm{O}_{2}$ for Hydrolysis and oxidative degradation and were stressed at variable temperature for variable time period for kinetic study. Aliquots of 0.5 $\mathrm{ml}$ of the sample solutions were withdrawn at different time intervals, neutralized with equivalent strength of $\mathrm{NaOH} / \mathrm{HCl}$. Suitable dilutions were made to produce concentration $\mathrm{C}_{0}=12 \mu \mathrm{g} / \mathrm{spot}$, filtered through $0.2 \mu$ membrane syringe filter, applied, developed and scanned by optimized chromatographic conditions. The concentrations of drug remaining were calculated from the formula: $\% \mathrm{Deg}=$ [initial area of untreated stock solution - reduced area of treated stock solution]/ Initial area of untreated stock solution * 100

The degradation rate kinetics were determined using linear and nonlinear regression analysis. The rate constant $\left(\mathrm{K}_{\mathrm{obs}}\right)$, half-life $\left({ }_{\mathrm{t} 1 / 2}\right)$ and activation energy $(\mathrm{Ea})$ were calculated. In the present study linear and nonlinear fit function from GraphPad Prism program was used.

\section{RESULT AND DISCUSSION}

\section{Method development and optimization by Risk based and QbD approach}

The ishikawa diagram (Figure 2) shows the variables that may affect the method performance characteristics. In the present study, a Cause-Effect Risk Assessment Matrix with CNX approach was utilized (supplementary file 1). Based on risk assessment three CMVs were identified to have significant influence on method performance. These are Mobile phase composition (MPC), chamber saturation time (CST) and migration distances (MD), that were further subjected to BBD to identify optimized chromatographic condition. Table 1 shows the factors with their levels and selected responses used for BBD. The matrixes of BBD with their measured responses are provided in supplementary file 2 .

\section{Statistical Analysis and Inferences}

The ANOVA (Table 2) results showed highly statistical significant difference between the model terms $(\mathrm{p}<0.05)$, high $\mathrm{r}^{2}$ value, insignificant lack of fit, and lower values of PRESS. The significant factors were selected from half normal probability plot. Further, the polynomial regression equations generated for each of the studied responses RS1, RS2 and Rf were assessed for the model terms and interacting variables. Coefficients for each model terms and each factor were analyzed to identify influence of each variable and their interactions on magnitude of responses (supplementary

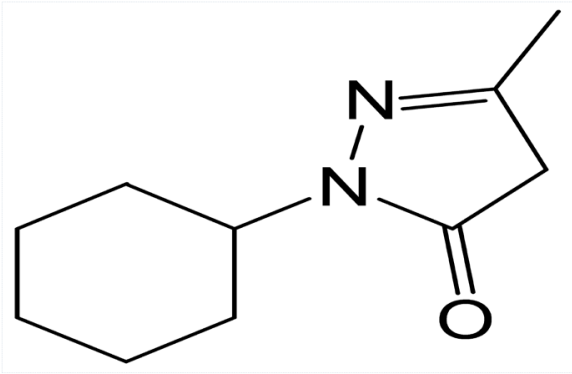

Figure 1: Structure of Edaravone

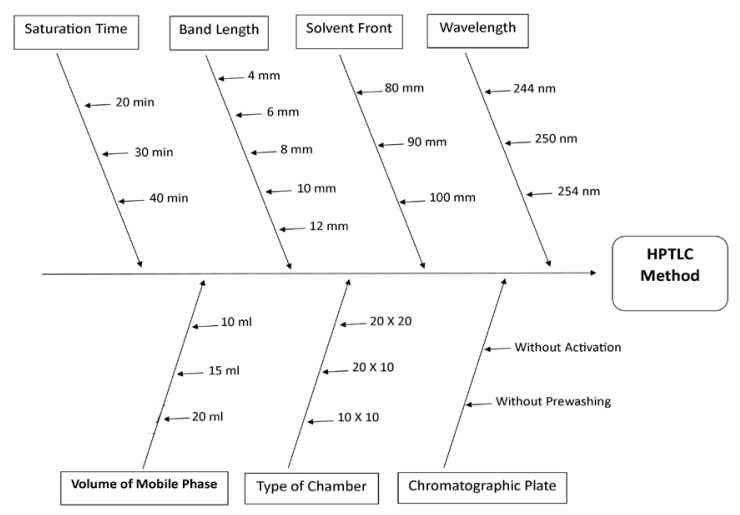

Figure 2: Ishikawa or fish bone diagram of HPTLC method.

Table 1: Variables and their levels for Box Behenken Design

\begin{tabular}{|c|c|c|}
\hline Factors & Coded Levels & $\begin{array}{l}\text { Actual } \\
\text { Levels }\end{array}$ \\
\hline \multirow{2}{*}{$\begin{array}{l}\text { A: Chamber Saturation time } \\
\text { (min) }\end{array}$} & -1 & 20 \\
\hline & 1 & 40 \\
\hline \multirow[t]{2}{*}{ B: Migration distance $(\mathrm{mm})$} & -1 & 80 \\
\hline & 1 & 100 \\
\hline \multirow{2}{*}{$\begin{array}{l}\text { C: Mobile phase composition } \\
\text { (Ratio of Petroleum Ether) }\end{array}$} & -1 & 4 \\
\hline & 1 & 8 \\
\hline \multicolumn{2}{|l|}{ Responses } & Constraints \\
\hline \multicolumn{2}{|c|}{ R1: resolution between DP-1 and DP-2 (RS1) } & $0.08 \leq \mathrm{R} 1 \geq 0.1$ \\
\hline \multicolumn{2}{|c|}{ R2: : resolution between DP-2 and DP-3 (RS2) } & $0.08 \leq R 2 \geq 0.1$ \\
\hline \multicolumn{2}{|c|}{ R3: Retardation Factor of EDA (Rf) } & $0.3 \leq R 3 \geq 0.5$ \\
\hline
\end{tabular}


file 3). Model equations for the studied response variables are as given below:

$\mathrm{RS} 1=+0.12-5.625 \mathrm{E}-003 * \mathrm{~A}+0.054 * \mathrm{C}-9.500 \mathrm{E}-$ 003* $\mathrm{A} * \mathrm{C}-0.019 * \mathrm{~A}^{2}-0.051 * \mathrm{C}^{2}$

$\mathrm{RS} 2=+0.10+0.015 * \mathrm{~A}+7.125 \mathrm{E}-003 * \mathrm{~B}-0.042 * \mathrm{C}+$ 9.500E-003*A*C $+0.015 * \mathrm{~B}^{*} \mathrm{C}-8.000 \mathrm{E}-003 * \mathrm{~B}^{2}-$ $0.027 * \mathrm{C}^{2}$

$\mathrm{Rf}=+0.44+0.087 * \mathrm{~B}-0.28 * \mathrm{C}-0.049 * \mathrm{~B}^{2}+0.19 * \mathrm{C}^{2}$

The magnitude of the coefficients in the equation and the $\mathrm{p}$-value $(<0.001)$ indicated that the factors A and C significantly affected the response RS1. The significant interaction effect was AC. For response RS2 all factors i. e. A, B, C affected significantly and significant interaction effects were $\mathrm{AC}$ and $\mathrm{BC}$. For response Rf, $\mathrm{B}$ and $\mathrm{C}$ significantly affected, and interaction effects were not observed. There is reasonable good agreement between the adjusted and predicted $r^{2}$ value for all responses. The optimum conditions were calculated by using numerical optimization. To achieve the composite desirability (di) the response criteria were set as, in range (0.09-0.1) for RS1 and RS2 and in range (0.3-0.5), for Rf. Derringer's desirability was calculated and the final optimum solution was selected (i.e. CST-22 m, MD- 89 mm, MPC5.8). The desirability and overlay plots are provided in supplementary file 4. The experimental results along with 95\% Confidence interval (CI) and prediction interval $(\mathrm{PI})$ values for selected responses were lie within range. The fairly good agreement between experimental and predicted results shows the robustness of the selected model.

The reliability of the selected model was evaluated using cross-validation. The predicted, experimental values and $\%$ bias for responses are provided in supplementary file 5. Lower values of $\%$ bias indicate the validity of model and were calculated by the Equation: Bias $=($ Predicted value - Experimental value)/ Predicted value

The optimized conditions obtained by using $\mathrm{QbD}$ were then used to obtain the final chromatograms that

\begin{tabular}{|c|c|c|c|c|c|c|c|c|c|c|c|}
\hline Response & Model & ss & DF & MS & F-value & p-value & PRESS & r2 & Adj-r2 & Pred-r2 & $\mathbf{A P}$ \\
\hline RS1 & RQM & 0.037 & 5 & 7.441E-003 & 48.61 & $<0.0001$ & 6.689E-003 & 0.9567 & 0.9370 & 0.8280 & 17.860 \\
\hline RS2 & RQM & 0.021 & 7 & 3.026E-003 & 70.59 & $<0.0001$ & 2.664E-003 & 0.9821 & 0.9682 & 0.8765 & 26.775 \\
\hline RF & RQM & 0.82 & 4 & 0.20 & 54.14 & $<0.0001$ & 0.11 & 0.9475 & 0.9300 & 0.8771 & 21.738 \\
\hline $\begin{array}{l}S S=\text { Sum of } S \\
D F=\text { Degrees } \\
M S=\text { Mean of } \\
\text { PRESS = pred }\end{array}$ & $\begin{array}{l}\text { vares } \\
\text { f freedom } \\
\text { quare } \\
\text { tion error }\end{array}$ & of sque & & & & $\begin{array}{l}\text { Adj- } r 2=A d \\
\text { Pred- } r 2=P \\
A P=A d e q u \\
R O M=\text { redu }\end{array}$ & $\begin{array}{l}\text { Jsted } r_{2} \\
\text { edicted } r_{2} \\
\text { te Precision } \\
\text { ed quadratic mo }\end{array}$ & & & & \\
\hline
\end{tabular}

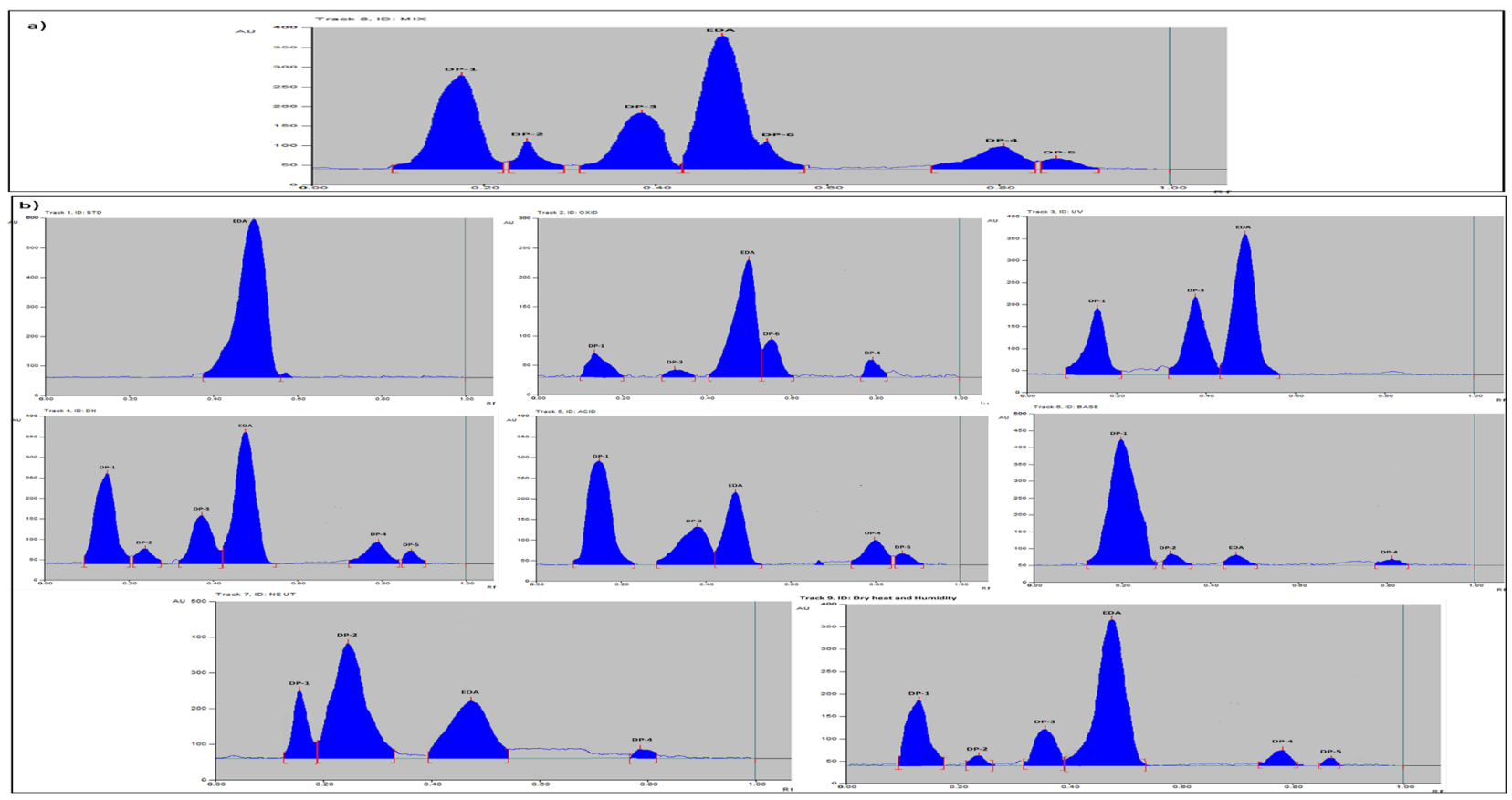

Figure 3: a) Optimized chromatogram showing resolved peaks in mixture of degradants in API, b) Chromatograms of stress degradations of Edaravone in different stress conditions 
showed good resolution, selectivity, and symmetrical peaks and are shown in Figure 3a.

\section{Method validation}

\section{Linearity and Range}

The linearity of the method was investigated in the concentration range of $2-24 \mu \mathrm{g} / \mathrm{spot}$ of EDA. The $\mathrm{r}^{2}$ value was found to be 0.998 . The overlay chromatogram and calibration curve is shown in Figure 4.

\section{Precision}

The \% RSD of repeatability and reproducibility were found to be 0.742 and 0.957 respectively.

\section{Limit of detection and quantitation (LOD and LOQ)}

The LOD and LOQ of the present method were found to be 0.327 and $0.989 \mu \mathrm{g} /$ spot respectively.

\section{Specificity}

The chromatogram of blank solution did not show any spot, while the chromatogram of the solution of the injection spiked with EDA gives clear and compact chromatogram of drug. No other peaks were eluted, therefore the method is considered to be specific.

\section{Recovery studies}

Standard addition method (corresponding to $80 \%$, $100 \%$, and $120 \%$ ) was utilized to determine recovery of EDA from formulation matrix. The Values of recovery $(\%)$ and SD are found to be $100.27 \pm 0.0503,99.88$ \pm 0.1123 and $99.93 \pm 0.1113$ respectively.

\section{Robustness of the method}

Robustness of the developed chromatographic method was determined by introducing small changes in the chamber saturation time, mobile phase composition, plate activation time, migration distance and volume of mobile phase. The effects on the results were examined that showed very slight changes in the peak area and Rf. The lower values \%RSD indicates the robustness of method and shown in Table 3.

\section{Stress degradation study}

Stress degradation was carried out with bulk drug. Six DPs were formed in mixture of degradants (Figure 3a). The drug was found to be degraded under all stressed conditions. EDA was highly unstable when subjected to oxidation. The degradation conditions, $\%$ of degradation along with number of DPs formed are presented in Table 4. The chromatograms of individual stress degradations are shown in Figure $3 \mathrm{~b}$.

\section{Application of developed method:}

The proposed chromatographic method was used to estimate the content of EDA in commercially available formulation. The method is selective for analysis of $\mathrm{EDA}$, as no interference from the excipients was found. The proposed chromatographic method was utilized to analyze stability of EDA formulation. Stress degradation were carried out under same condition as specified for bulk drug and analyzed in the same way. The degradation products were well resolved with distinct Rf value. Minor variation was observed in \% degradation of bulk drug and formulation (Table 4).

\section{Degradation kinetic study}

The degradation kinetic of EDA was investigated in acid, base, neutral and oxidative degradation. The linear regression analysis was performed for neutral and oxidative degradation, while acid and base degradation followed nonlinear regression analysis at the selected temperature and concentration.

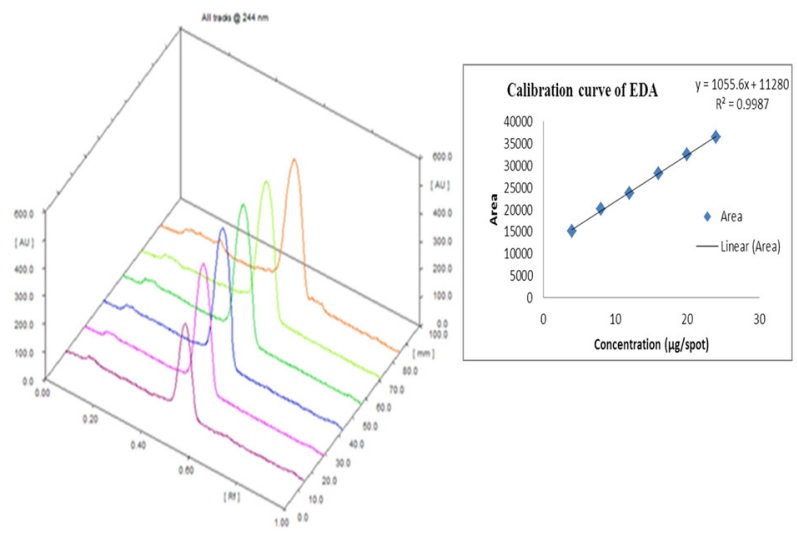

Figure 4: Overlay chromatogram showing linearity of developed method

Table 3: Results of Robustness study

\begin{tabular}{l|l|l} 
Parameter & \%RSD (Area) & \%RSD (Rf)
\end{tabular}

Chamber Saturation Time

\begin{tabular}{l|l|l}
$20 \mathrm{~min}$ & 0.44 & 0.66 \\
\hline $25 \mathrm{~min}$ & 0.56 & 0.75
\end{tabular}

Mobile Phase Composition Pet ether-Ethyl acetate-GAA

\begin{tabular}{|c|c|c|}
\hline 6.0:4.0:10 $\mu \mathrm{l}, \mathrm{v} / \mathrm{v} / \mathrm{v} / \mathrm{v}$ & 0.44 & 0.72 \\
\hline 6.0:4.0:15 $\mu \mathrm{l}, \mathrm{v} / \mathrm{v} / \mathrm{v} / \mathrm{v}$ & 0.38 & 0.69 \\
\hline 5.6:4.4:10 $\mu \mathrm{l}, \mathrm{v} / \mathrm{v} / \mathrm{v} / \mathrm{v}$ & 0.45 & 0.75 \\
\hline 5.6:4.4:15 $\mu \mathrm{l}, \mathrm{v} / \mathrm{v} / \mathrm{v} / \mathrm{v}$ & 0.74 & 0.99 \\
\hline \multicolumn{3}{|l|}{ Plate activation } \\
\hline $15 \min$ & 0.45 & 0.66 \\
\hline $25 \mathrm{~min}$ & 0.50 & 0.57 \\
\hline \multicolumn{3}{|l|}{ Volume of Mobile phase } \\
\hline $8 \mathrm{ml}$ & 0.24 & 0.54 \\
\hline $12 \mathrm{ml}$ & 0.41 & 0.66 \\
\hline \multicolumn{3}{|l|}{ Migration Distance } \\
\hline $88 \mathrm{~mm}$ & 0.69 & 0.76 \\
\hline $90 \mathrm{~mm}$ & 0.51 & 0.77 \\
\hline
\end{tabular}


Kinetics of neutral and oxidative degradation

Both neutral and oxidative degradation followed zero order degradation kinetic (Figure $5 \mathrm{a}$ and $5 \mathrm{~b}$ ) at selected concentration and temperature. The calculated rate constants were given in Table 5. Plot of \% Degradation verses time gives the value of rate constant (estimated from slopes). The resulting $\mathrm{K}_{\text {obs }}$ values were plotted against temperature (in kelvin) to obtain Arrhenius plot which is presented in Fig. 5c for neutral degradation.

\section{Kinetics of acid and base degradation}

For both acid and base degradation nonlinear regression analysis (Figure 5d and 5e) was performed for pseudo first order degradation kinetics at selected temperature and concentration as it fits better than linear regression analysis. Both acid and base degradation were assumed to follow pseudo first order degradation kinetic since the $r^{2}$ value is highest for second order process and the concentration of the stressor was much higher and constant during whole degradation process. The estimates of $\mathrm{K}_{\text {obs }}$ and $\mathrm{t}_{1 / 2}$ (Table 5) can be obtained directly by plotting logarithm of observed \% degradation vs time data in nonlinear regression analysis using graphpad prism. The Arrhenius plots are shown in Figure $5 \mathrm{f}$ and $5 \mathrm{~g}$ for acid and base degradation respectively.

\begin{tabular}{|c|c|c|c|c|c|}
\hline Stressor Type & Stressor Concentration & Time & $\begin{array}{l}\% \text { Degradation } \\
\text { (API) }\end{array}$ & $\begin{array}{c}\text { \% Degradation } \\
\text { (Formulation) }\end{array}$ & DPs Formed \\
\hline Acid Degradation & $0.05 \mathrm{~N} \mathrm{HCl}$ at $800 \mathrm{C}$ & $180 \mathrm{~m}$ & 63.51 & 61.24 & $\begin{array}{c}\text { DP-1, DP-3, DP-4, } \\
\text { DP-5 }\end{array}$ \\
\hline Base Degradation & $0.8 \mathrm{~N} \mathrm{NaOH}$ at $800 \mathrm{C}$ & $180 \mathrm{~m}$ & 69.34 & 67.09 & DP-1, DP-2, DP-4 \\
\hline Neutral Degradation & $1000 \mathrm{C}$ & $7 \mathrm{~h}$ & 45.55 & 44.91 & DP-1, DP-2, DP-4 \\
\hline Oxidative Degradation & $6 \% \mathrm{H} 2 \mathrm{O} 2$ at $\mathrm{RT}$ & $45 \mathrm{~m}$ & 52.08 & 50.80 & $\begin{array}{c}\text { DP-1, DP-3, DP-4, } \\
\text { DP-6 }\end{array}$ \\
\hline Photolytic Degradation & $\begin{array}{c}5382 \text { LUX and 144UW/ } \\
\mathrm{cm} 2\end{array}$ & 21 days & 62.85 & 61.23 & DP-1, DP-3 \\
\hline $\begin{array}{l}\text { Dry Heat induced } \\
\text { Degradation }\end{array}$ & $80^{\circ} \mathrm{C}$ & 21 days & 67.42 & 20.41 (for $72 \mathrm{~h}$ ) & $\begin{array}{c}\text { DP-1, DP-3, DP-4, } \\
\text { DP-5 }\end{array}$ \\
\hline $\begin{array}{l}\text { Thermal/ humidity } \\
\text { induced Degradation }\end{array}$ & $40^{\circ} \mathrm{C} 70+5 \% \mathrm{RH}$ & 21 days & 27.59 & 29.04 & $\begin{array}{c}\text { DP-1, DP-3, DP-4, } \\
\text { DP-5 }\end{array}$ \\
\hline
\end{tabular}
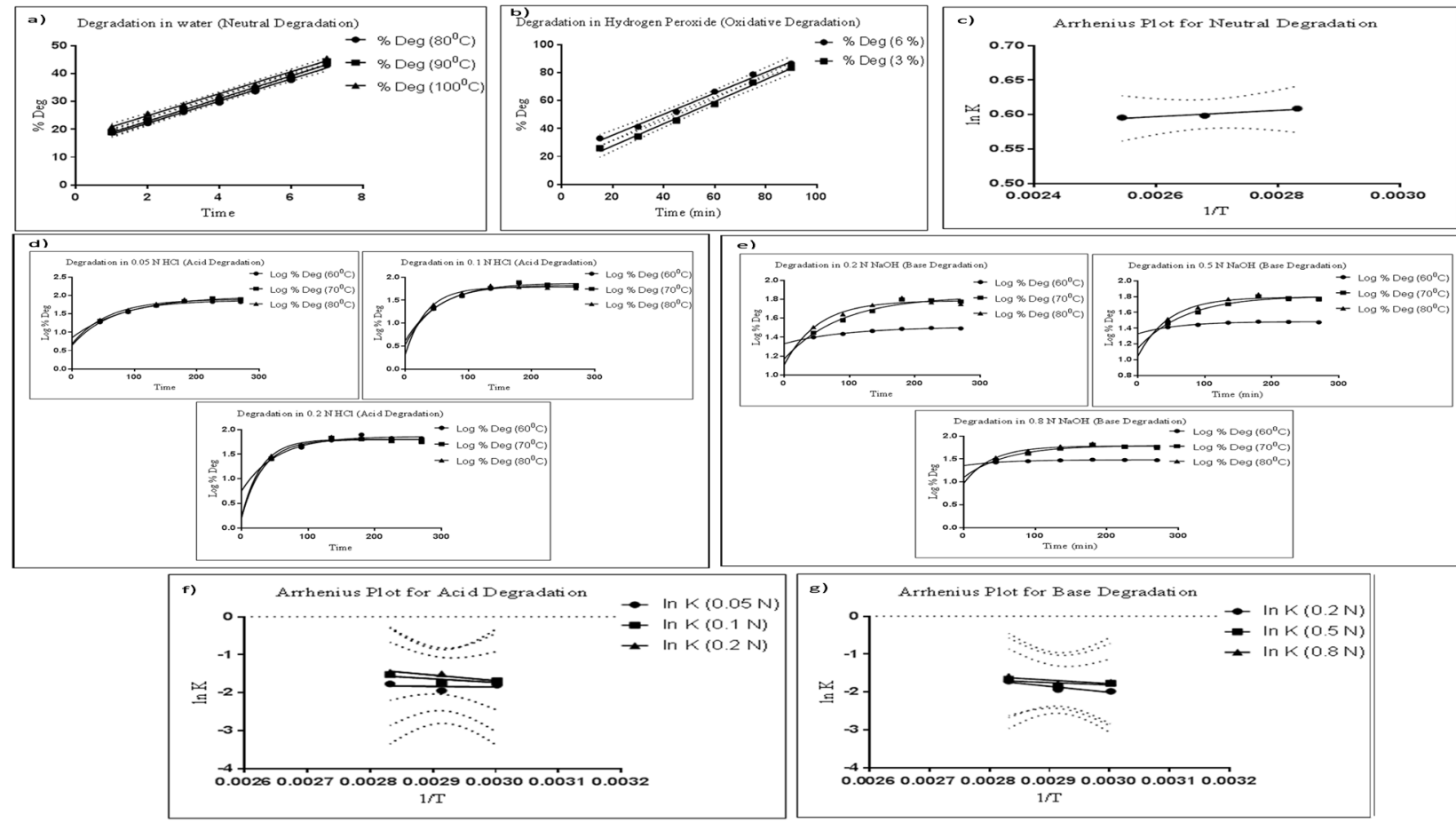

Figure 5: a) Linear zero order kinetic plot for neutral degradation, b) Linear zero order kinetic plot for oxidative degradation, c) Arrhenius plot for neutral degradation, d) Non-linear pseudo first order degradation kinetic plot for acid degradation, e) Nonlinear pseudo first order degradation kinetic plot for base degradation, f) Arrhenius plot for acid degradation g) Arrhenius plot for base degradation. 


\begin{tabular}{|c|c|c|c|c|c|c|c|c|c|}
\hline Parameter & \multicolumn{9}{|c|}{ Experimental values } \\
\hline Stressor & \multicolumn{9}{|c|}{ Neutral Degradation } \\
\hline Temperature & \multicolumn{3}{|c|}{$\left(80^{\circ} \mathrm{C}\right)$} & \multicolumn{3}{|c|}{$\left(90^{\circ} \mathrm{C}\right)$} & \multicolumn{3}{|c|}{$\left(100^{\circ} \mathrm{C}\right)$} \\
\hline Concentration & \multicolumn{3}{|c|}{--NA-- } & \multicolumn{3}{|c|}{--NA-- } & \multicolumn{3}{|c|}{--NA-- } \\
\hline r2 & \multicolumn{3}{|c|}{0.9957} & \multicolumn{3}{|c|}{0.9931} & \multicolumn{3}{|c|}{0.995} \\
\hline Kobs & \multicolumn{3}{|c|}{3.966} & \multicolumn{3}{|c|}{4.062} & \multicolumn{3}{|c|}{3.942} \\
\hline $\mathrm{t} 1 / 2(\min )$ & \multicolumn{3}{|c|}{203.0594} & \multicolumn{3}{|c|}{198.2802} & \multicolumn{3}{|c|}{197.0606} \\
\hline Ea & \multicolumn{9}{|c|}{0.3797} \\
\hline Stressor & \multicolumn{9}{|c|}{ Oxidative Degradation } \\
\hline Temperature & \multicolumn{3}{|c|}{--NA-- } & \multicolumn{3}{|c|}{--NA-- } & \multicolumn{3}{|c|}{-} \\
\hline Concentration & \multicolumn{3}{|c|}{$6 \%$} & \multicolumn{3}{|c|}{$3 \%$} & \multicolumn{3}{|c|}{-} \\
\hline r2 & \multicolumn{3}{|c|}{0.9928} & \multicolumn{3}{|c|}{0.9933} & \multicolumn{3}{|c|}{--} \\
\hline Kobs & \multicolumn{3}{|c|}{0.7504} & \multicolumn{3}{|c|}{0.7915} & & -- & \\
\hline $\mathrm{t} 1 / 2(\min )$ & & -- & & & -- & & & -- & \\
\hline $\mathrm{Ea}$ & & & & . & & & & & \\
\hline Stressor & & & & Acid Deg & dation & & & & \\
\hline temperature & & $\left(60^{\circ} \mathrm{C}\right)$ & & & $\left(70^{\circ} \mathrm{C}\right)$ & & & $\left(80^{\circ} \mathrm{C}\right)$ & \\
\hline concentration & $0.05 \mathrm{~N}$ & $0.1 \mathrm{~N}$ & $0.2 \mathrm{~N}$ & $0.05 \mathrm{~N}$ & $0.1 \mathrm{~N}$ & $0.2 \mathrm{~N}$ & $0.5 \mathrm{~N}$ & $0.1 \mathrm{~N}$ & $0.2 \mathrm{~N}$ \\
\hline $\mathrm{R} 2$ & 0.9977 & 0.9892 & 0.9873 & 0.9989 & 0.974 & 0.9793 & 0.9958 & 0.958 & 0.9519 \\
\hline Kobs & 0.0159 & 0.0205 & 0.0193 & 0.0114 & 0.0182 & 0.0314 & 0.0170 & 0.0300 & 0.0345 \\
\hline $\mathrm{t} 1 / 2(\min )$ & 43.49 & 33.76 & 35.79 & 61.05 & 38.05 & 22.01 & 40.72 & 23.05 & 20.09 \\
\hline $\mathrm{Ea}$ & & -1.20 & & & -7.94 & & & -12.37 & \\
\hline Strssor & & & & Base De & dation & & & & \\
\hline temperature & & $\left(60^{\circ} \mathrm{C}\right)$ & & & $\left(70^{\circ} \mathrm{C}\right)$ & & & $\left(80^{\circ} \mathrm{C}\right)$ & \\
\hline concentration & $0.2 \mathrm{~N}$ & $0.5 \mathrm{~N}$ & $0.8 \mathrm{~N}$ & $0.2 \mathrm{~N}$ & $0.5 \mathrm{~N}$ & $0.8 \mathrm{~N}$ & $0.2 \mathrm{~N}$ & $0.5 \mathrm{~N}$ & $0.8 \mathrm{~N}$ \\
\hline $\mathrm{R} 2$ & 0.9847 & 0.9682 & 0.9439 & 0.9818 & 0.9825 & 0.9778 & 0.964 & 0.9623 & 0.9289 \\
\hline Kobs & 0.0112 & 0.0174 & 0.0184 & 0.0147 & 0.0172 & 0.0198 & 0.0219 & 0.0244 & 0.0283 \\
\hline $\mathrm{t} 1 / 2(\min )$ & 66.44 & 41.07 & 38.39 & 59.76 & 48.92 & 41.26 & 35.67 & 31.79 & 26.77 \\
\hline $\mathrm{Ea}$ & & -13.10 & & & -5.27 & & & -7.53 & \\
\hline
\end{tabular}

\section{CONCLUSION}

As there is no reported stability indicating TLC-densitometry method for edaravone, the goal of present work was achieved by implementing the risk based and systematic QbD approach to resolve and quantitate Edaravone in presence of its degradation products in bulk and injection formulation. The developed TLCdensitometry method has been validated as per ICH guidelines for the determination of the drug without any interference from excipients and in presence of degradation products. The method provides significant sensitivity as well as reduced sample preparation and instrument run time over other separation methods. Also the method offers advantages such as short system equilibrium time, possibility of simultaneous analysis of samples and standard on the same plate, higher mobile phase $\mathrm{pH}$ and minimum solution consumption. Hence the method appears to be suitable for routine analysis and for quality control in the pharmaceutical industry due to its simplicity, sensitivity and selectivity.

\section{ACKNOWLEDGEMENT}

The authors are thankful to UGC for providing UGCBSR (RFSMS) fellowship to carryout the present work.

\section{CONFLICT OF INTEREST}

None

\section{ABBREVIATION USED}

EDA: Edaravone; $\mathrm{HCl}$ : Hydrochloric acid; $\mathrm{NaOH}$ Sodium hydroxide; $\mathrm{H}_{2} \mathrm{O}_{2}$ : Hydrogen peroxide; QbD: Quality by design; ATP: Analytical target profile; BBD: Box behenkan design; ICH: International conference of harmonization; Deg: Degradation; MPC:mobile phase composition; CST: chamber saturation time; $\mathrm{MD}$ : 
migration distance; Rf: Retardation factor; LOD: Limit of detection; LOQ: Limit of quantification; RSD: Relative standard deviation.

\section{REFERENCES}

1. Watanabe T, Tahara M, Todo S. The Novel Antioxidant Edaravone: From Bench to Bedside. Cardiovascular Therapeutics. 2008;26(2):101-14.

2. Edaravone Acute Infarction Study Group. Effect of a novel free radical scavenger, edaravone (MCl-186), on acute brain infarction. Randomized, placebo-controlled, double-blind study at multicenters. Cerebrovasc. Dis. 2003;15(3):222-229.

3. Watanabe T, Yuki S, Egawa M, Nishi H. Protective effects of MCl-186 on cerebral ischemia: possible involvement of free radical scavenging and antioxidant actions. J Pharmacol Exp Ther. 1994;268(3):1597-604

4. Yamamoto T, Yuki S, Watanabe T, Mitsuka M, Saito KI. Delayed neuronal death prevented by inhibition of increased hydroxyl radical formation in a transient cerebral ischemia. Brain Res. 1997;762(1):240-242.

5. Lapchak PA, Zivin JA. The lipophilic multifunctional antioxidant edaravone (radicut) improves behavior following embolic strokes in rabbits: a combination therapy study with tissue plasminogen activator. Exp Neurol. 2009;215(1):95-100.

6. Araki Y, Andoh A, Fujiyama Y. The free radical scavenger edaravone suppresses experimental dextran sulfate sodium-induced colitis in rats. Int J Mol Med. 2003:12:125-9.

7. Saibara T, Toda K, Wakatsuki A, Ogawa Y, Ono M, Onishi S. Protective effect of 3-methyl-1-phenyl-2-pyrazolin-5-one, a free radical scavenger, on acute toxicity of paraquat in mice. Toxicol Lett. 2003;143(1):51-4.
8. Patel B, Raj H, Jain V. Simultaneous estimation of edaravone and citicoline sodium by ratio derivative spectroscopic method in synthetic mixture. Pharma Science Monitor. 2014;5(2):118-28.

9. Ping L, Zheng Yu Y, Zhi Ji X, Xiao S. A novel fluorescent assay for edaravone with aqueous functional CdSe quantum dots. Spectrochemica Acta Part A: Mol. and Biomol. Spectro. 2009;72(5):75.

10. Li jin lin. Determination of Phenyl hydrazine Residues in Edaravone by HPLC. J China Pharmacy. 2008;31:2454-5.

11. Fanse S, Rajput SJ. Development and Validation of A Simple UV Spectrophotometric And Isocratic RP-HPLC Method For Estimation of Edaravone in Bulk and its Injection Formulation. Indo American Journal of Pharm Research. 2015;5(01):584-92.

12. Patel BK, Raj HA, Jain VC, Sutariya V, Bhatt M, Patel K. Method development and validation of RP-HPLC for simultaneous estimation of edaravone and citicoline sodium in synthetic mixture. Invent rapid J. Pharm Analysis and Quality Assurance. 2014;3:104-114.

13. Gandhimathi M, Kumar MS, Baghla R, Ravi TK. RP-HPTLC Method for the In vitro Estimation of Edaravone in Human Plasma. Indian J Pharma Sci. 2010;72(2):276-82.

14. Daoquan T. LC-MS/MS methods for the determination of Edaravone and/or taurine in rat plasma and its application to a pharmacokinetic study. Biomed Chromatogr. 2014;28(9):1173-82.

15. Panda SS, Beg S, Kumar R, Bera VV, Singh P. Analytical Quality-By-Design Compliant Ultrafast Liquid Chromatographic Method for Determination of Paliperidone in Extended Release Tablet Dosage Form. J Bioanal Biomed. 2015;7(4):116-23.

16. International Conference on Harmonization, Q2(R1) Validation of Analytical Procedures: Methodology, Consensus Guidelines, ICH Harmonized Tripartite Guidelines, 1996

\section{SUMMARY}

- Stability indicating $\mathrm{QbD}$ based TLC-densitometry method was developed and validated as per $\mathrm{ICH}$ guidelines. Edaravone was subjected to $\mathrm{ICH}$ prescribed stress degradation conditions and was found to be susceptible under all conditions. The Rf value of Edaravone was $0.46 \pm 0.21$ and the method was found to be linear over the range of $04-24 \mu \mathrm{g} / \mathrm{band}$. The LOD and LOQ were found to be 0.327 and $0.989 \mu \mathrm{g} / \mathrm{spot}$ respectively. Linear and non-linear regression analysis was performed to determine degradation kinetic. The kinetics of acid and base degradation followed non-linear kinetics while neutral and oxidative degradation followed linear degradation kinetic.

\section{About Authors}

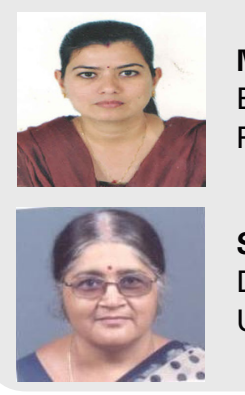

Madhuri Baghel: Research Scholar, Quality Assurance Laboratory, Centre of Relevance and Excellence in Novel Drug Delivery System, Faculty of Pharmacy, G. H. Patel Building, Donor's Plaza, The Maharaja Sayajirao University of Baroda, Fatehgunj, Vadodara - 390002, Gujarat, India

Sadhana Rajput: Proff. Quality Assurance, Centre of Relevance and Excellence in Novel Drug Delivery System, Faculty of Pharmacy, G. H. Patel Building, Donor's Plaza, The Maharaja Sayajirao University of Baroda, Fatehgunj, Vadodara - 390002, Gujarat, India

Cite this article: Baghel M, Rajput S. Development of Stability Indicating TLC-Densitometry Method of Edaravone Using QbD Approach: Degradation Kinetic Study. Indian J of Pharmaceutical Education and Research. 2017;51(2S):S61-S8. 